\title{
Ischemia-Induced Apoptosis of Intestinal Epithelial Cells Correlates with Altered Integrin Distribution and Disassembly of F-Actin Triggered by Calcium Overload
}

\author{
Zhenyi Jia, ${ }^{1}$ Qian Chen, ${ }^{2}$ and Huanlong Qin ${ }^{1}$ \\ ${ }^{1}$ Department of General Surgery, Shanghai Sixth People's Hospital, Shanghai Jiao Tong University, Shanghai 200233, China \\ ${ }^{2}$ Department of General Surgery, Shanghai Minhang Centre Hospital, Shanghai 201100, China \\ Correspondence should be addressed to Huanlong Qin, hlqin65@hotmail.com
}

Received 11 January 2012; Accepted 23 March 2012

Academic Editor: Dominic Fan

Copyright (C) 2012 Zhenyi Jia et al. This is an open access article distributed under the Creative Commons Attribution License, which permits unrestricted use, distribution, and reproduction in any medium, provided the original work is properly cited.

\begin{abstract}
The present study examined intestinal epithelial cell (IEC) integrin distribution and disassembly of actin cytoskeleton in response to ischemia-anoxia. Protective effects of calcium channel blocker(CCB) were further examined to explore underlying mechanisms of cellular injury. Materials and Methods. Primary cultures of rat IECs and an in vitro model of ischemia/anoxia were established. IECs were exposed to ischemia/anoxia in the presence and absence of verapamil. The extent of exfoliation was determined using light microscopy while apoptosis rate was measured using flow cytometry. Changes in intracellular calcium, the distribution of integrins and the morphology of F-actin were assessed by confocal microscopy. Results. Detachment and apoptosis of IECs increased following ischemia/anoxia-induced injury. Treatment with verapamil inhibited the detachment and apoptosis. Under control conditions, the strongest fluorescent staining for integrins appeared on the basal surface of IECs while this re-distributed to the apical membrane in response to ischemic injury. Depolymerization of F-actin was also observed in the injured cells. Verapamil attenuated both changes of integrins and F-actin. Conclusions. Redistribution of integrins and disruption of F-actin under ischemia/anoxia injury is associated with IEC detachment and increased apoptosis. These events appeared to be triggered by an increase in $\mathrm{Ca}^{2+}{ }_{i}$ suggesting a potential use for CCB in prevention and treatment of intestinal injury.
\end{abstract}

\section{Introduction}

In recent years, a number of studies have indicated that the intestinal mucosa is the first affected site under shock or other low blood flow conditions $[1,2]$. Apoptosis, a form of cell death distinct from necrosis, appears to play a key role in the intestinal injury response to the ischemia and anoxia associated with these conditions. The resultant cell death may then lead to loss of the gut barrier function and the translocation of bacteria [3]. To date, however, the exact cellular mechanisms involved in the pathogenesis of intestinal ischemia and anoxia injury remain unclear.

Ischemia and anoxia result in an increased $\mathrm{Ca}^{2+}$-influx through plasma membrane calcium channels resulting in accumulation of large quantities of intracellular $\mathrm{Ca}^{2+}\left[\mathrm{Ca}^{2+}\right]_{i}$ [4-7]. Such an increase in $\left[\mathrm{Ca}^{2+}\right]_{i}$ has been proposed to be the major mediator leading to apotosis in various cell types including, cardiomyocytes, neurons, renal cells, and colonic cells [4-7]. As calcium channel blockers can reduce the accumulation of calcium by decreasing its entry, it is therefore conceivable that these inhibitors could attenuate $\mathrm{Ca}^{2+}$-induced apoptosis. Consistent with this a number of studies have reported an inhibitory effect of calcium channel blockers on apoptosis following ischemia-induced injury. Thus, verapamil, a commonly used L-type calcium channel blocker, has proven effective in decreasing apoptosis in an experimental model of renal ischemia [8]. Similarly, the alternate $\mathrm{Ca}^{2+}$ channel blocker, benidipine, exerts a significant antiapoptotic effect during ischemia/reperfusioninduced damage of myocardial cells [9]. As a result of these studies, we examined the effectiveness of $\mathrm{Ca}^{2+}$ entry blockade on apoptosis in rat-cultured intestinal epithelial cells (IECs) exposed to ischemic conditions.

In addition to changes in $\left[\mathrm{Ca}^{2+}\right]_{i}$ the role of cell anchorage for cell survival is widely appreciated. For example, when 
TABLE 1: Extent of exfoliation and apoptosis.

\begin{tabular}{lcc}
\hline & Exfoliation (\%) & Apoptosis (\%) \\
\hline Group A & $4.8 \pm 1.6$ & $34.5 \pm 3.6$ \\
Group B & $17.6 \pm 6.8^{* *}$ & $68.6 \pm 4.2^{* *}$ \\
Group C & $25.6 \pm 8.2^{\# \#}$ & $55.6 \pm 4.2^{\# \#}$ \\
\hline
\end{tabular}

A: control; B: ischemia/anoxia treated; C: ischemia/anoxia treated + verapamil. $n=6$ per group

** Group A versus Group B, $P<0.01$; ${ }^{\#}$ Group B versus Group C, $P<0$.

TABLe 2: (a) Intracellular $\mathrm{Ca}^{2+}$ levels using fluorescence intensity. (b) Intracellular $\mathrm{Ca}^{2+}$ levels using fluorescence intensity.

(a)

\begin{tabular}{lc}
\hline & intracellular calcium (arbitrary units) \\
\hline Group A & $142 \pm 13$ \\
Group B & $287 \pm 41^{* *}$ \\
Group C & $195 \pm 56^{\# \#}$ \\
\hline
\end{tabular}

A: control; B: ischemia/anoxia treated; C: ischemia/anoxia treated + verapamil. $n=6$ per group

** Group A versus Group B, $P<0.01$; \# Group B versus Group C, $P<0.01$.

(b)

\begin{tabular}{lc}
\hline & Relative fluorescence intensity $\left(\mathrm{F} / \mathrm{F}_{0} \%\right)$ \\
\hline Group A & 100 \\
Group B & $203 \pm 5.84^{* *}$ \\
Group C & $145 \pm 4.28^{\# \#}$ \\
\hline
\end{tabular}

A: control; B: ischemia/anoxia treated; C: ischemia/anoxia treated + verapamil. $n=6$ per group

** Group A versus Group B, $P<0.01 ;{ }^{\#}$ Group B versus Group C, $P<0.05$.

epithelial cells are completely deprived of cell anchorage to their underlying extracellular matrix, they undergo a form of apoptosis termed "anoikis" [10]. As anoikis plays an important role in cell turnover and cell migration of IECs [11], it is conceivable that during ischemic injury these mechanisms are involved. Integrins exist as $\alpha$ and $\beta$ subunit heterodimeric cell-surface receptors that mediate cell-ECM interactions, regulating both cell adhesion and survival. Furthermore, suppression of integrin activity can lead to weakening of cell adhesion and subsequent apoptosis [12-14].

The cytoplasmic domain of the $\beta$ integrin chain is linked via cytoplasmic adaptor proteins, such as talin, to the actin cytoskeleton. This connection is required for integrins to perform their varied roles. Supporting this, recent studies have demonstrated that cytoskeletal rearrangements that accompany integrin-mediated adhesion and cell shape changes contribute to the abrogation of anoikis $[15,16]$. However, the role of integrins and actin in IECs in ischemia/anoxiainduced injury has not yet been reported. Thus, in the current study we used laser scanning confocal microscopy, together with a model of ischemia/anoxia in murine IECs, to observe the involvement of integrins and actin. Furthermore, to define underlying cellular mechanisms we explored the effect of calcium channel blocker on these changes.

\section{Materials and Methods}

2.1. Animal Handling and Cell Culture. All protocols were approved by the Committee of Ethics for Experimentation, Shanghai Sixth People's Hospital. Pregnant Sprague Dawley rats were obtained from the Shanghai Laboratory Animal Center. Rats were anesthetized with an intraperitoneal injection of ketamine $(60 \mathrm{mg} / \mathrm{kg})$ after which fetal rats were obtained by cesarean section, and their small intestines were removed. IECs were isolated and cultured using a modification of the method of Evans et al. [17]. Briefly, intestines were cut into small pieces and digested for $10 \mathrm{~min}$ at $22^{\circ} \mathrm{C}$ on a shaker platform in $\mathrm{Ca}^{2+}$ - and $\mathrm{Mg}^{2+}$-free Hanks-Balanced Salt Solution HBSS containing $60 \mathrm{U}$ of collagenase XIa (Sigma, St. Louis, Mo.) per mL, $0.02 \mathrm{mg}$ of dispase I (Boehringer Mannheim, Indianapolis, Ind.) per $\mathrm{mL}, 2 \%$ bovine serum albumin, and $0.2 \mathrm{mg}$ of soybean trypsin inhibitor (Sigma) per $\mathrm{mL}$. Cells and small sheets of intestinal epithelium were separated from the denser intestinal fragments by harvesting supernatants after two $60 \mathrm{sec}$ centrifugations $(100 \times \mathrm{g})$. Cells were then centrifuged five times at $120 \times \mathrm{g}$ for $3 \mathrm{~min}$ in Dulbecco's modified Eagle medium (DMEM; (Gibco BRL, Grand Island, New York, USA) plus $2 \%$ sorbitol. The remaining pellet, consisting predominantly of cells in intact crypts and small sheets of intestinal epithelium, was plated $\left(1 \times 10^{6}\right.$ cells $\left./ \mathrm{mL}\right)$ in 6 -well culture dishes with or without glass coverslips in the bottom of the dish. The glass coverslips or the bottom surfaces of dishes were previously coated with Matrigel (Collaborative Biomedical Products, Bedford, Mass.). The culture medium consisted of a mixture of DMEM, $10 \%$ sorbitol, $100 \mathrm{U}$ of penicillin per $\mathrm{mL}, 100 \mu \mathrm{g}$ of streptomycin per $\mathrm{mL}$, and $5 \%$ fetal bovine serum (FBS) (Biowhittaker, Walkerville, Md.). Cells were cultured in $5 \% \mathrm{CO}_{2}$ at $37^{\circ} \mathrm{C}$ with periodic supplementation of medium to maintain a constant volume of $8 \mathrm{~mL}$ per well and replacement twice a week. Cell growth and morphology were assessed by light and transmission electron microscopy.

\subsection{Electrophysiological Recording of Calcium Currents.} Macroscopic $\mathrm{Ba}^{2+}$ currents were recorded using the patchclamp technique, in the whole-cell configuration, with an HEKA EPC 9 amplifier and Patchmaster acquisition software. Data were lowpass filtered at $2.9 \mathrm{kHz}$ and acquired at $20 \mathrm{kHz}$. The final resistance of the electrode filled with the pipette solution (described below) was 3-8 M 2 . Capacitative transients and access resistance were automatically compensated for using the acquisition software.

Prior to electrophysiological recording, the culture medium was removed and replaced with extracellular solution containing (in $\mathrm{mM}$ ) $60 \mathrm{CsCl}, 50 \mathrm{NaCl}, 20 \mathrm{TEA}-\mathrm{Cl}$, $20 \mathrm{BaCl} 2,2$ 4-AP, 10 HEPES, $2 \mathrm{MgCl}_{2}, 10 \mathrm{D}$-glucose, and $500 \mathrm{nM}$ TTX (pH was adjusted with $\mathrm{NaOH}$ to 7.3 , and osmolarity was adjusted to $290-310 \mathrm{mmol} / \mathrm{kg}$ ). Pipettes were filled with solution containing (in $\mathrm{mM}$ ) $135 \mathrm{CsCl}, 10$ TEA$\mathrm{Cl}, 3 \mathrm{MgCl}_{2}, 10 \mathrm{HEPES}, 10$ EGTA, $3 \mathrm{Na}$-ATP, and $0.3 \mathrm{Na}-$ GTP ( $\mathrm{pH}$ was adjusted with $\mathrm{CsOH}$ to 7.3 , and osmolarity was adjusted to $290-310 \mathrm{mmol} / \mathrm{kg}$ ). Nifedipine, used as an Ltype calcium channel blocker, was solubilized in DMSO, and 
TABLE 3: (a) Fluorescence intensity of integrin $\alpha 3$ in different planes of the IEC (A: control group; B: injury group; C: verapamil group; plane 1 to 5: from the basal surface to the apical surface). (b) Fluorescence intensity of integrin $\alpha 5$ in different 1 planes of the IEC (A: Control group B: Injury group; C: Verapamil group; plane 1 to 5: from the basal surface to the apical surface). (c) Fluorescence intensity of integrin $\beta 1$ in different planes of the IEC (A: Control group; B: Injury group; C: Verapamil group; planes 1 to 5: from the basal surface to the apical surface). (d) Fluorescence intensity of integrin $\beta 5$ in different planes of the IEC (A: Control group; B: Injury group; C: Verapamil group; planes 1 to 5: from the basal surface to the apical surface). (e) Fluorescence intensity of integrin $\alpha 2$ in different planes of the IEC (A: Control group B: Injury group; C: Verapamil group; planes 1 to 5: from the basal surface to the apical surface).

(a)

\begin{tabular}{lccccc}
\hline & 1 & 2 & 3 & 4 & 5 \\
\hline Group A & $122 \pm 11$ & $82 \pm 6$ & $69 \pm 4$ & $46 \pm 3$ & $30 \pm 3$ \\
Group B & $92 \pm 7^{*}$ & $91 \pm 3^{*}$ & $78 \pm 1^{*}$ & $56 \pm 5^{*}$ & $47 \pm 5^{*}$ \\
Group C & $102 \pm 10^{* \#}$ & $81 \pm 6^{*}$ & $77 \pm 7^{*}$ & $50 \pm 6$ & $39 \pm 4^{* \#}$ \\
\hline
\end{tabular}

${ }^{*} P<0.05$ versus Group A; ${ }^{\#} P<0.05$ versus Group B; $n=10$.

(b)

\begin{tabular}{lccccc}
\hline & 1 & 2 & 3 & 4 & 5 \\
\hline Group A & $113 \pm 12$ & $84 \pm 11$ & $77 \pm 6$ & $71 \pm 8$ & $50 \pm 2$ \\
Group B & $86 \pm 15^{*}$ & $85 \pm 12$ & $85 \pm 10^{*}$ & $89 \pm 6^{*}$ & $80 \pm 19^{*}$ \\
Group C & $98 \pm 11^{* \#}$ & $91 \pm 11$ & $84 \pm 8$ & $83 \pm 10^{*}$ & $69 \pm 13^{*} \#$ \\
\hline
\end{tabular}

${ }^{*} P<0.05$ versus Group A; ${ }^{*} P<0.05$ versus Group B; $n=10$.

(c)

\begin{tabular}{lccccc}
\hline & 1 & 2 & 3 & 4 & 5 \\
\hline Group A & $206 \pm 12$ & $141 \pm 10$ & $110 \pm 7$ & $61 \pm 10$ & $40 \pm 5$ \\
Group B & $139 \pm 13^{*}$ & $165 \pm 11^{*}$ & $150 \pm 15^{*}$ & $119 \pm 18^{*}$ & $85 \pm 9^{*}$ \\
Group C & $170 \pm 10^{* \#}$ & $160 \pm 9^{*}$ & $130 \pm 10^{* \#}$ & $90 \pm 11^{\text {*\# }}$ & $72 \pm 14^{* \#}$ \\
\hline *\#
\end{tabular}

${ }^{*} P<0.05$ versus Group A; ${ }^{\#} P<0.05$ versus Group B; $n=10$.

(d)

\begin{tabular}{lccccc}
\hline & 1 & 2 & 3 & 4 & 5 \\
\hline Group A & $126 \pm 9$ & $91 \pm 6$ & $83 \pm 6$ & $77 \pm 1$ & $60 \pm 3$ \\
Group B & $99 \pm 20^{*}$ & $103 \pm 19^{*}$ & $97 \pm 21^{*}$ & $93 \pm 8^{*}$ & $89 \pm 14^{*}$ \\
Group C & $107 \pm 19^{* \#}$ & $97 \pm 10$ & $91 \pm 25^{*}$ & $89 \pm 15^{*}$ & $79 \pm 5^{* \#}$ \\
\hline
\end{tabular}

${ }^{*} P<0.05$ versus Group A; ${ }^{*} P<0.05$ versus Group B; $n=10$.

(e)

\begin{tabular}{lccccc}
\hline & 1 & 2 & 3 & 4 & 5 \\
\hline Group A & $59 \pm 3$ & $53 \pm 3$ & $60 \pm 4$ & $58 \pm 1$ & $54 \pm 2$ \\
Group B & $54 \pm 1$ & $54 \pm 2$ & $59 \pm 3$ & $59 \pm 2$ & $50 \pm 1$ \\
Group C & $55 \pm 4$ & $56 \pm 2$ & $55 \pm 3$ & $63 \pm 4$ \\
\hline
\end{tabular}

$n=10$.

diluted in the extracellular solution to a final concentration of $5 \mu \mathrm{M}$.

Solutions were exchanged using a gravity-fed perfusion system, with the delivery pipette placed within $100 \mu \mathrm{m}$ of the patched cell. The cell membrane was held at $-70 \mathrm{mV}$, and stimulated every $20 \mathrm{~s}$ with a voltage ramp, which increased from $-70 \mathrm{mV}$ to $90 \mathrm{mV}$ over $100 \mathrm{~ms}$.

2.3. Ischemia/Anoxia Stimulation of IECs. Cultured IECs were subjected to ischemia and anoxia conditions by immediately replacing culture fluid with PBS solution in the AnaeroPack jar (AnaeroPack Series,Mitsubishi Gas Chemical
Co, Inc), which is equipped with an AnaeroPack, disposable $\mathrm{O}_{2}$-absorbing and $\mathrm{CO}_{2}$-generating agent, and an indicator to monitor oxygen depletion as previous study. The AnaeroPack jar is capable of reducing $\mathrm{O}_{2}$ concentrations to $<0.1 \%$ in 2 hours and of providing a $21 \% \mathrm{CO}_{2}$ atmosphere (evident when the indicator color changes from pink to white) [18].

2.4. Cell Treatments. After seven days in culture, IECs were divided into control (A), injury (B), and verapamil (C) groups. Group B IECs were incubated under ischemia/anoxia conditions for $4 \mathrm{~h}$ while Group C IECs were similarly incubated in the presence of verapamil $(4 \mu \mathrm{M})$ for $4 \mathrm{~h}$. 
2.5. Extent of Exfoliation. Following treatment, the shed cells were removed with medium. The medium was centrifuged at $1000 \mathrm{rpm}$ for $5 \mathrm{~min}$, then the precipitate was resuspended in $1 \mathrm{~mL}$ PBS, and a drop of trypan blue solution was added. The number of shed cells was obtained by counting the number of blue-stained cells. Undetached IECs in flasks were digested by $0.25 \%$ trypsin. After centrifugation at $1000 \mathrm{rpm}$ for $5 \mathrm{~min}$, the precipitate was collected and resuspended in $1 \mathrm{~mL}$ PBS to count the number of cells. The extent of exfoliation was expressed as the percentage of shed cells to the total cell number.

2.6. Detection of Apoptosis. To detect apoptosis, cells were stained with propidium iodide (PI) and fluoresceinisothiocyanate- (FITC-) conjugated annexin V using an Annexin V-FITC/PI Apoptosis Detection Kit. Coulter flow cytometer was used to measure the FITC fluorescence between 515 and $545 \mathrm{~nm}$ and the PI fluorescence between 564 and $606 \mathrm{~nm}$. Apoptotic cells were defined as cells staining positively for FITC and negative for PI.

2.7. Measurement of Intracellular Calcium Levels. Intracellular $\mathrm{Ca}^{2+}$ levels were monitored using the $\mathrm{Ca}^{2+}$-sensitive fluorescent indicator, Fluo-3. Cultured IECs on glass coverslips were loaded with Fluo-3/AM $(5 \mu \mathrm{mol} / \mathrm{L})$ in HBSS buffer at room temperature for $30 \mathrm{~min}$. After washing twice with fresh HBSS, the cells were placed in $0.5 \mathrm{~mL}$ HBSS buffer and the cell fluorescence intensity was examined using a confocal laser scanning microscope (Bio-Rad Radiance 2100). A $488 \mathrm{~nm}$ excitation wavelength provided by an argon laser was used to illuminate Fluo-3, and fluorescence was detected at emission wavelength $510 \mathrm{~nm}$ and above. Changes in $\mathrm{Ca}^{2+}$ levels were represented by relative fluorescence intensity $\left(\mathrm{F} / \mathrm{F}_{0} \%\right)$ where $\mathrm{F} 0$ represents the fluorescence levels measured in control cells while $\mathrm{F}$ was that measured in the injury or verapamil treated groups.

2.8. Changes in Integrin Distribution. Following exposure to ischemic/anoxic conditions, cells were washed with PBS and fixed in $3.7 \%$ formaldehyde for $30 \mathrm{~min}$. After washing twice with PBS, cells were incubated with antibodies to rat $\alpha 2, \alpha 3$, $\alpha 5, \beta 1$, and $\beta 5$ integrins (Sigma, St. Louis, Mo.) $(0.5 \mathrm{~mL}$, diluted $1: 100)$ for $60 \mathrm{~min}$ at room temperature. Cells were then incubated with an FITC-labeled sheep anti-rat IgG (Sigma, St. Louis, Mo.) $(0.5 \mathrm{~mL}$, diluted 1 : 100) for $60 \mathrm{~min}$ at room temperature in the dark. Cells were then washed twice in PBS at room temperature and mounted on slides with $5 \mu \mathrm{L}$ Gel/Mount mounting medium. Fluorescence analysis was performed using a confocal laser scanning microscope (BioRad Radiance 2100) and analyzed using Bio-Rad LaserSharp 2000 software. One-micron $z$-series optical sections were taken from the basal to the apical surface of the cells and stored on optical discs. Distribution of integrins subunit was determined by quantifying the fluorescence intensity. This was performed by drawing polygonal regions of interest on each cell layer in which average integrated fluorescence levels were obtained. Background fluorescence was eliminated by adjusting the image fluorescence intensity to a fixed threshold level.
2.9. Visualization of the Actin Cytoskeleton. After exposure of cells to the ischemic/anoxic conditions, adherent IECs were fixed for $30 \mathrm{~min}$ in $3.7 \%$ formaldehyde in $\mathrm{Ca}^{2+}$ - and $\mathrm{Mg}^{2+}$-containing PBS (Sigma). The cells were subsequently washed six times in PBS and then permeabilized for $5 \mathrm{~min}$ with $0.2 \%$ Triton X-100 in PBS. Cells were then washed in PBS and immersed in fresh PBS, to which had been added $5 \mu \mathrm{g} \mathrm{mL}-1$ of F-actin binding fluorescein-isothiocyanate(FITC-) labelled phalloidin (Sigma). The coverslips were maintained in the dark and incubated on a rocking platform for $60 \mathrm{~min}$. They were then washed twice in PBS at room temperature and mounted on slides with $5 \mu \mathrm{L}$ Gel/Mount mounting medium with $0.1 \%$ p-phenylenediamine (antiquench) to prevent photobleaching. The cells were then observed using the laser scanning confocal microscope.

2.10. Statistical Analysis. All data are expressed as mean \pm SEM. Experiments were repeated three times, with triplicate samples for each. Analysis of variance and appropriate post hoc testing was used to determine the level of significance for differences between means. Values of $P<0.05$ were regarded as statistically significant.

\section{Results}

3.1. Characteristics of Cultured IECs. The cultured cells showed a high degree of attachment and appeared slabstone shaped under light microscopy. Immunocytochemical characterization showed that more than $90 \%$ of the attached cells were positive for alkaline phosphatase (Figures 1(a) and $1(\mathrm{~b})$ ). Proliferating colonies of IECs coalesced to form large confluent areas of cells. In contrast, nonepithelial cells had a smooth-muscle-cell-like appearance, were present infrequently, and tended to be located at the edges of the IEC colonies or at the periphery of the well. Using the transmission electron microscope, numerous microvilli were observed on the surface of the IECs (Figure 1(c)). In addition, tight junctions, gap junctions, and desmosomes were evident between cells. In adherent cells the cytoskeleton was evident adjacent to the basement membrane with the appearance of focal adhesion forming. Apoptotic bodies were observed in some cells undergoing apoptosis (Figure 1(d)).

3.2. Electrophysiological Demonstration of L-Type VoltageGated $\mathrm{Ca}^{2+}$ Channels. To verify the presence of voltage-gated $\mathrm{Ca}^{2+}$ channels, cells underwent patch clamping. Cells showed voltage-sensitive $\mathrm{Ca}^{2+}$ currents that could be blocked by nifedipine ( $5 \mu \mathrm{M}$; Figure 2 ).

3.3. Extent of Exfoliation and Apoptosis. The extent of exfoliation and apoptosis in response to ischemia/anoxia is shown in Table 1 and Figure 3. Both parameters were significantly elevated in the injury group compared to the control group (ER: $25.6 \pm 8.2$ versus $4.8 \pm 1.6 \%, P<001$; AR: $68.6 \pm 4.2$ versus $34.5 \pm 3.6 \%, P<0.01)$. After treatment with verapamil, the IECs showed a significantly lower degree of detachment and apoptosis than those seen in the injury group (ER: $17.6 \pm 6.8$ versus $25.6 \pm 8.2 \%, P<005$; AR: $55.6 \pm 4.2$ versus $68.6 \pm 4.2, P<0.05)$. 


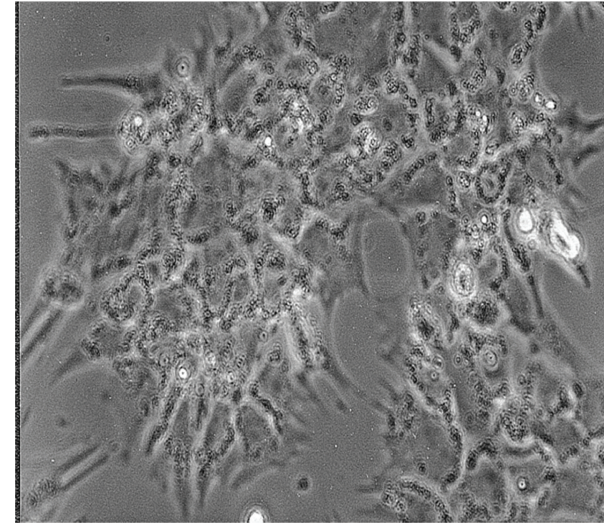

(a)

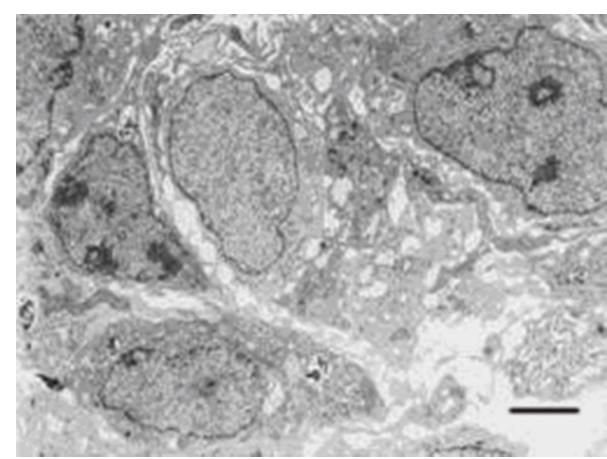

(c)

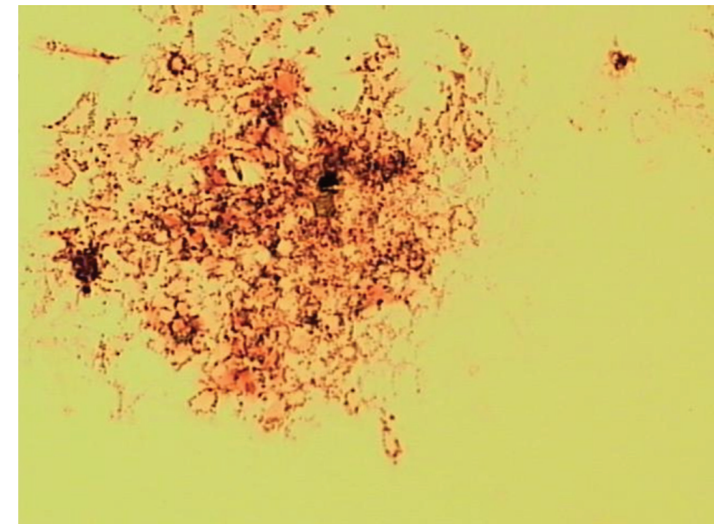

(b)

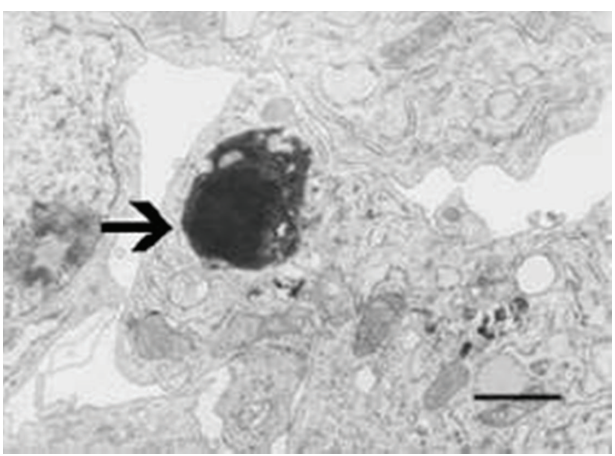

(d)

FIGURE 1: Cultured IEC exhibited a cobblestone morphology (light microscope 200x). (b) More than 90\% of the attached cells were positive for alkaline phosphatase (light microscope 200x). (c) Microvilli on the surface of the IEC (transmission electron microscope 5000x). (d) Apoptotic body (Arrowed) (Transmission electron microscope, 5000x). Scale bar $=2 \mu \mathrm{m}$.

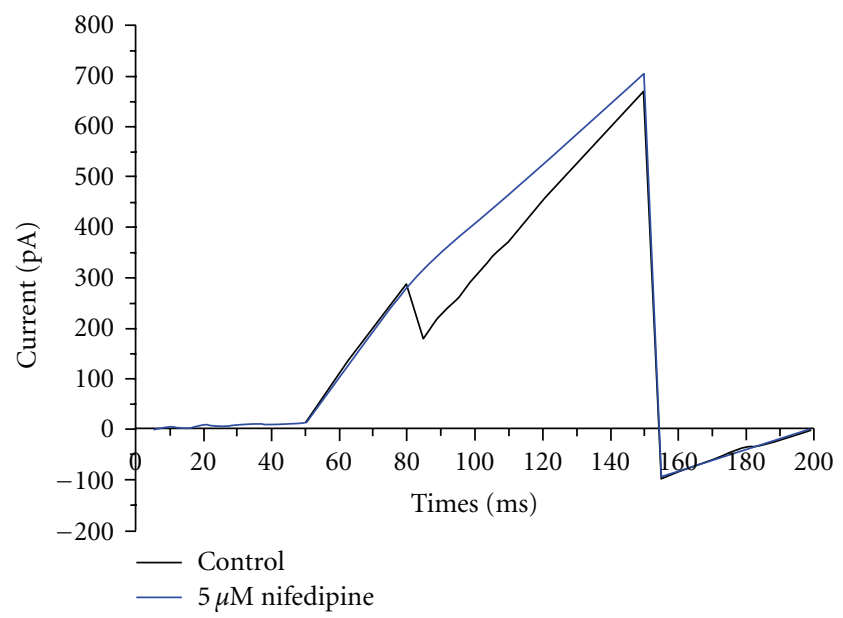

FIGURE 2: Representative traces show that depolarizing voltage steps elicited inward current in IECs and the inward current was inhibited by nifedipine $(5 \mu \mathrm{M})$.

3.4. Changes in Intracellular Calcium. Ischemia/anoxia induced a significant increase in $\mathrm{Ca}^{2+}{ }_{i}$ levels. Pretreatment with verapamil $(4 \mu \mathrm{M})$ significantly attenuated the rise in $\mathrm{Ca}^{2+}{ }_{i}$ levels that was observed in response to ischemia/anoxiainduced injury (Figure 4, Table 2).
3.5. Integrin Distribution. In the control group, $\alpha 3, \alpha 5$, $\beta 1$, and $\beta 5$ integrins in the first $z$-stack section showed the strongest fluorescence intensity, consistent with these subunits being predominantly located on the basal surface of IECs. In contrast, the apical plasma membrane showed only a slight fluorescence for these integrin subunits. After ischemia/anoxia injury, the fluorescence intensity on this first layer diminished while the intensity on the other layers increased, especially on the top-most layer which indicated these subunits altered their original distribution, moving to the apical surface of the cells. In verapamil-treated cells, the strongest fluorescence intensity was again located toward the basal surface demonstrating an inhibitory effect of the $\mathrm{Ca}^{2+}$ channel blocker on integrin redistribution (Figure 5, Table 3).

3.6. Effect of Ischemia/Anoxia on the Actin Cytoskeleton. The effect of ischemia/anoxia on organization of the actin cytoskeleton is shown in Figure 2. The control group showed a well-organized actin filament cytoskeleton consisting of thin bundles of stress fibers arranged across the cell bodies in a largely parallel pattern. In the ischemia/anoxia group, Factin bundles were not apparent and only clumps of F-actin clumps were visible, indicating depolymerization of the actin cytoskeleton. In contrast, when ischemia/anoxia group was pretreated with verapamil, the F-actin bundles appeared very 


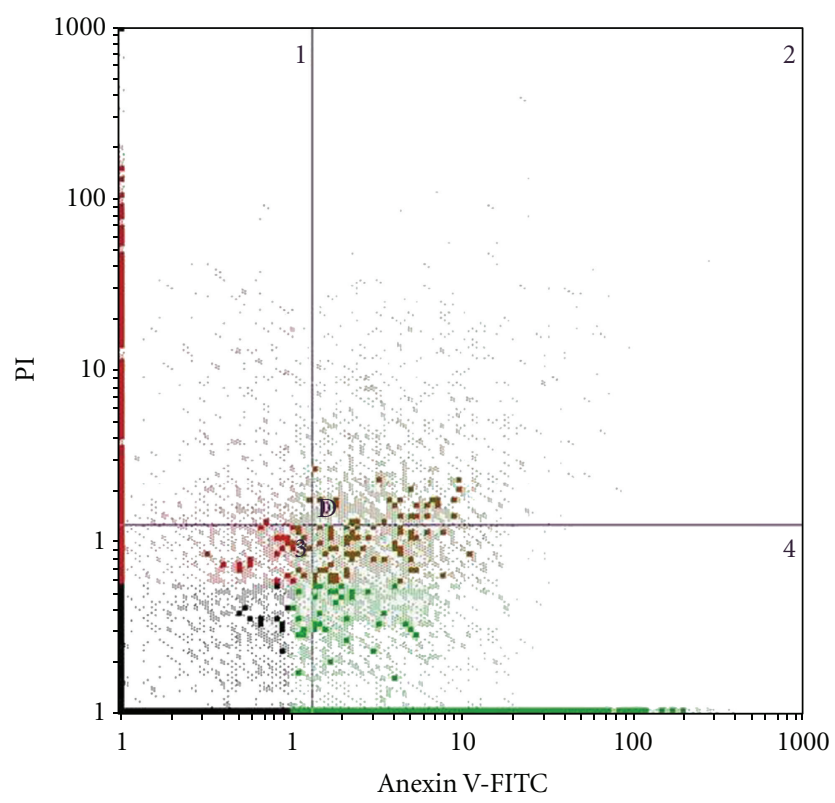

(a)

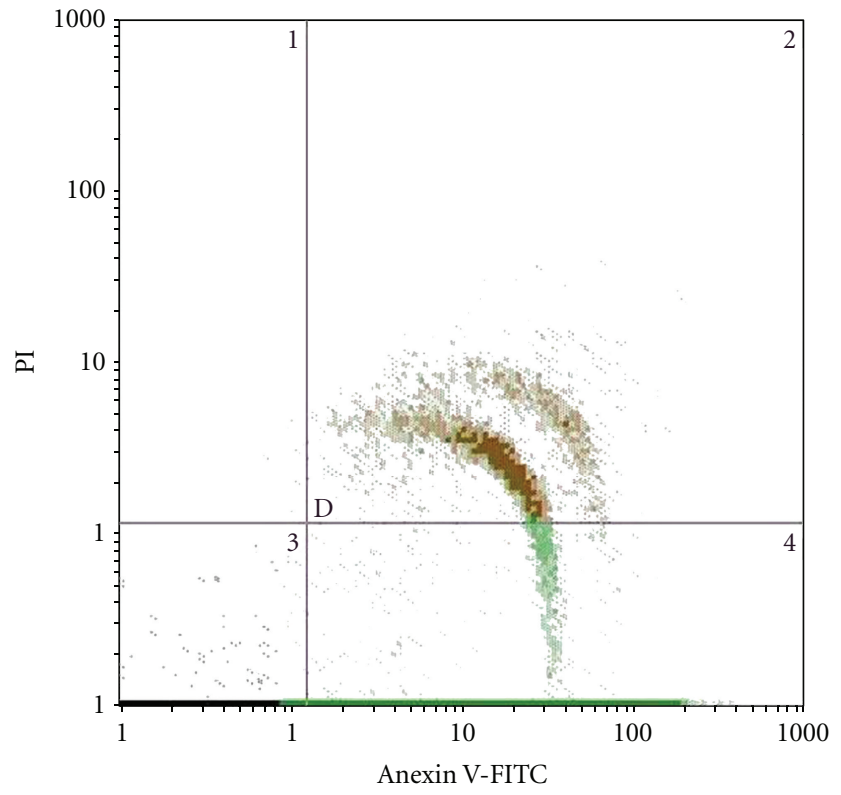

(b)

FIGURE 3: The FCM analyses following staining with annexin V-FITC and PI show the induction of apoptosis in IECs. Background labeling of living cells is found in quadrant 3, whereas quadrant 4 contains apoptotic cells, stained with annexin V-FITC only, and quadrant 2 represents cells that bind to annexin V and PI and is considered to be in late stages of apoptosis, exhibiting disrupted cell membrane or necrosis. Compared with cells in control group, the percentage of apoptotic cells increased in injury group. After treatment with verapamil, the percentage of apoptotic cells decreased compared with that in injury group.

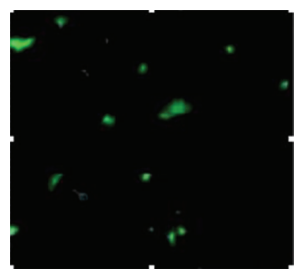

A

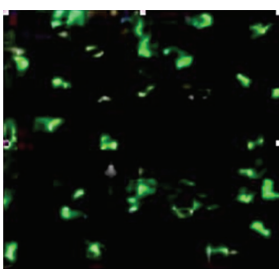

B

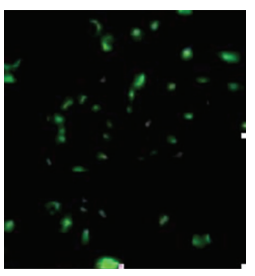

C

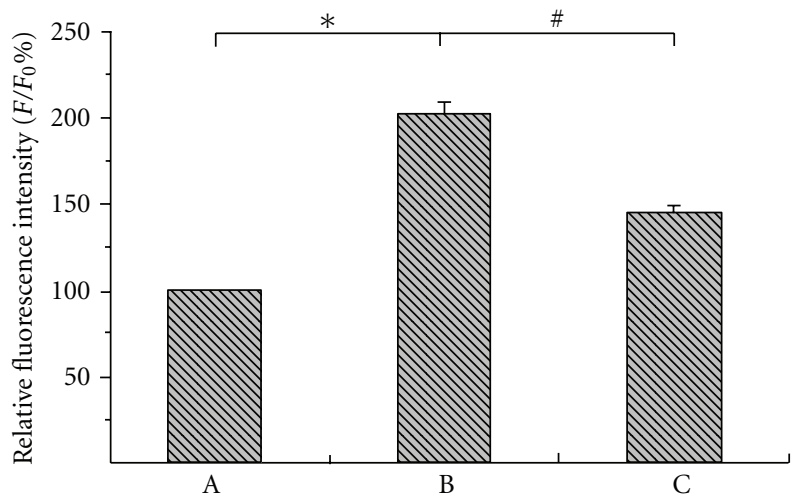

(b)

Figure 4: (a) Fluorescence images of $\left[\mathrm{Ca}^{2+}\right]_{i}$ changes as measured using a confocal microscope. A: control group; B: injury group; C: Verapamil-treated group. (b) The values represented the average relative fluorescence intensity $\left({ }^{*} P<0.01,{ }^{\#} P<0.05\right)$. A: control group; B: injury group; C: Verapamil-treated group.

similar to that of control animals, indicating that the $\mathrm{Ca}^{2+}$ channel blocker prevented the ischemia-induced alterations in the actin cytoskeleton (Figure 6).

\section{Discussion}

Injury resulting from ischemia/anoxia may cause significant structural alteration to the intestinal wall including disruption of the epithelial barrier through intestinal epithelial programmed cell death [19]. Several mechanisms have been proposed for the cellular basis of such ischemia/anoxia injury. These include an influx of calcium into cells resulting in an increase in cytosolic $\mathrm{Ca}^{2+}[20]$. The increased $\mathrm{Ca}^{2+}$ level subsequently manifests its cytotoxic effects on cells by altering mitochondrial respiratory function and energy metabolism. The results of the present study are consistent with this possible mechanism. Thus, we found increased intracellular $\mathrm{Ca}^{2+}$ levels in IECs under conditions 


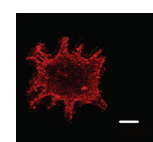

A1

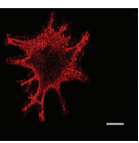

B1

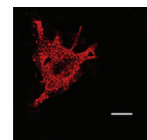

C1

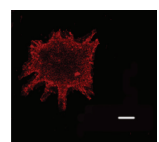

A2

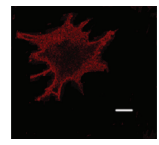

B2

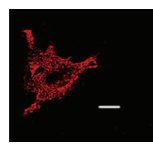

C2

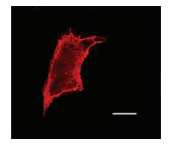

A1

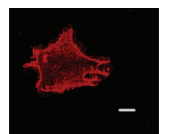

B1

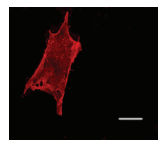

$\mathrm{C} 1$

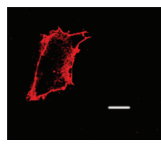

A2

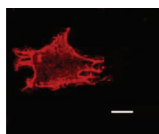

B2

$\mathrm{C} 2$
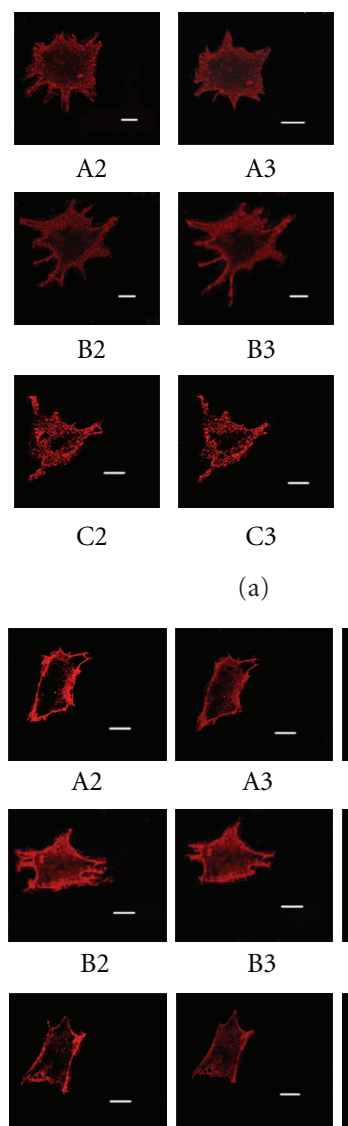

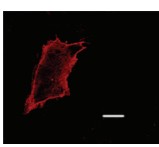

A3

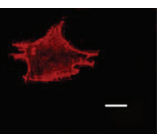

B3

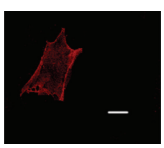

C3
A3

B3

C3

(a)

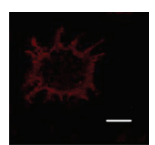

A4

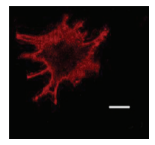

B4

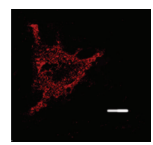

C4

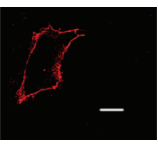

A4

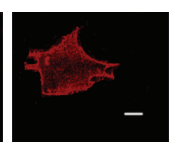

B4

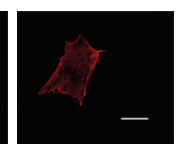

C4

(c)

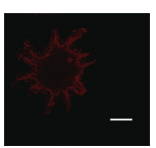

A5

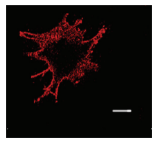

B5

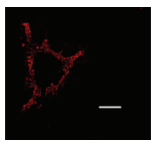

C5

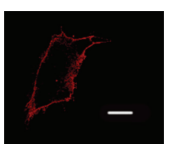

A5

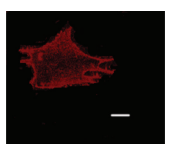

B5

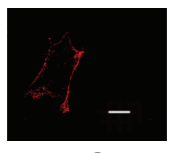

C5

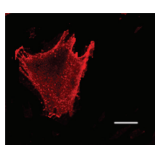

Al

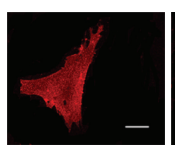

B1

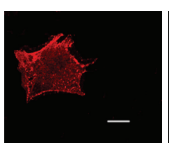

C1

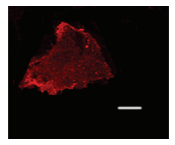

A1

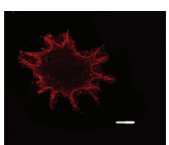

B1

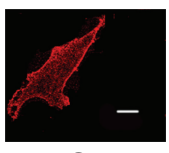

C1

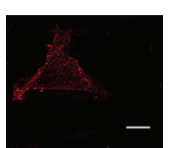

A1

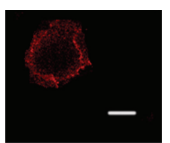

B1

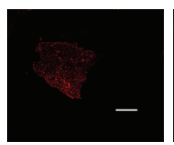

C1

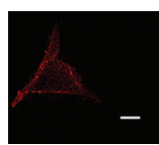

A2

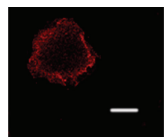

B2

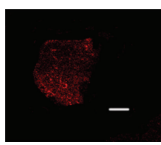

C2

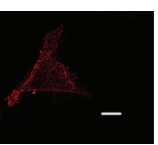

A3

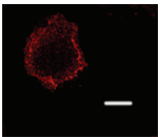

B3

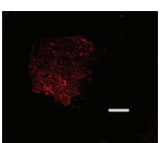

C3

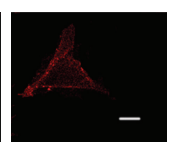

A4

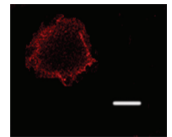

B4

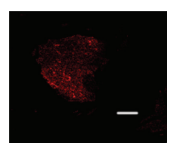

C4

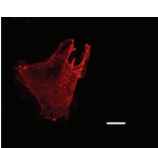

A2

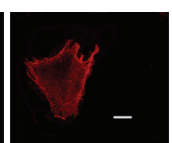

A3

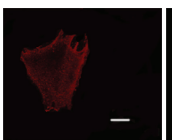

A4

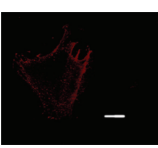

A5

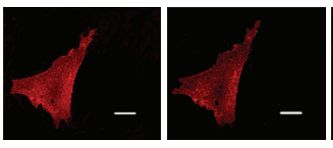

B2

B3

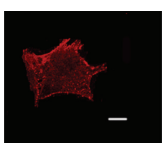

C2

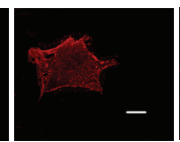

C3

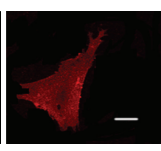

B4

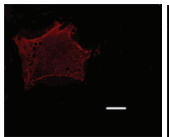

C4

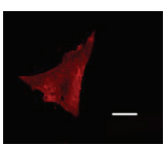

B5

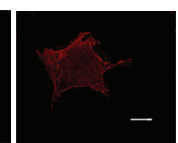

C5

(b)

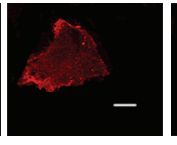

A2

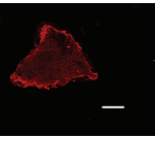

A3

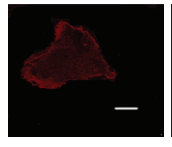

A4

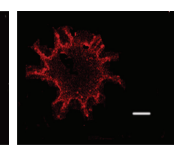

B3

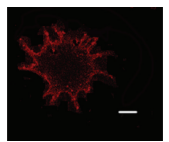

B4

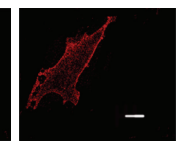

C3

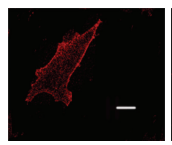

C4

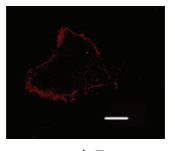

A5

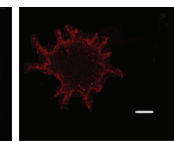

B5

(d)

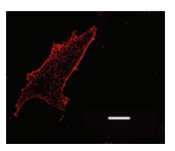

C5

(e)

FIGURE 5: (a) Fluorescence images of integrin $\alpha 3$ distribution (A: control group; B: injury group; C: verapamil-treated group; planes $1 \rightarrow 5$ : basal surface $\rightarrow$ apical surface; scale bar $=10 \mu \mathrm{m}$ ). (b) Fluorescence images of integrin $\alpha 5$ distribution (A: control group; B: Injury group; C: verapamil-treated group; planes $1 \rightarrow 5$ : basal surface $\rightarrow$ apical surface; scale bar $=10 \mu \mathrm{m}$ ). (c) Fluorescence images of integrin $\beta 1$ distribution (A: control group; B: injury group; C: verapamil group; planes $1 \rightarrow 5$ : basal surface $\rightarrow$ apical surface; scale bar $=10 \mu \mathrm{m}$ ). $(\mathrm{d}$ ) Fluorescence images of integrin $\beta 5$ distribution (A: Control group B: Injury group C: Verapamil group Planes $1 \rightarrow 5$ : basal surface $\rightarrow$ apical surface; scale bar $=10 \mu \mathrm{m}$ ). (e) Fluorescence images of integrin $\alpha 2$ distribution (A: control group; B: injury group; C: verapamil group; planes $1 \rightarrow 5$ : basal surface $\rightarrow$ apical surface; scale bar $=10 \mu \mathrm{m})$. 


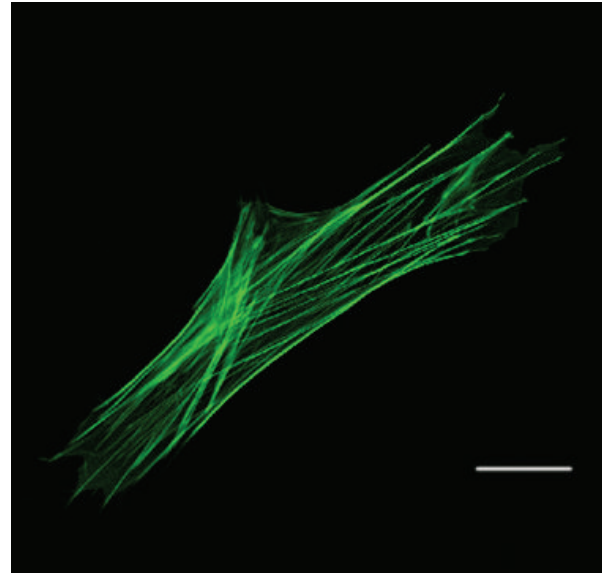

(a)

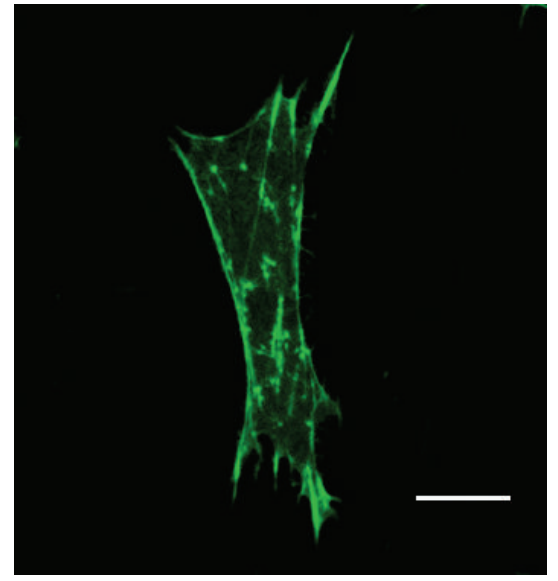

(b)

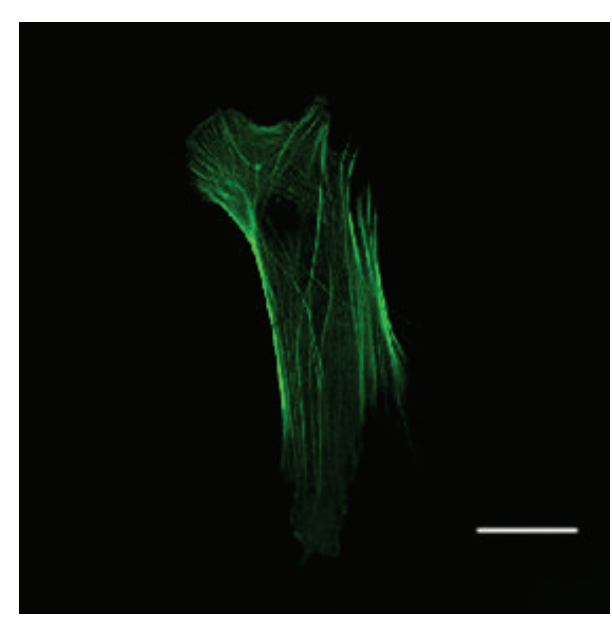

(c)

FIGURE 6: F-actin visualization by phalloidin labeling as analyzed by confocal microscopy. Scale bar = $10 \mu \mathrm{m}$ (A: control group; B: injury group; C: Verapamil-treated group).

of ischemia/anoxia which was associated with increased exfoliation and apoptosis. Following treatment with the Ltype $\mathrm{Ca}^{2+}$ channel blocker, verapamil, we found a significant decrease in both the rates of exfoliation and apoptosis together with a reduction of cytosolic calcium levels. This result indicated that calcium overload may be a trigger for IEC shedding and apoptosis during ischemia/anoxia injury. Furthermore, calcium channel inhibitors may be a potential means of prevention and treatment of intestinal dysfunction following ischemia/anoxia injury.

Integrins are a large family of cell-surface heterodimeric receptors involved in cell adhesion to the extracellular matrix. Differing $\alpha$ and $\beta$ integrin subunits are expressed in limited combinations and exhibit different ligand specificities. A variety of such integrin subunits have been detected in normal small intestine and colon, including $\alpha 2, \alpha 3, \alpha 5$, $\beta 1$, and $\beta 5$. The spatial distribution of for various integrins differs within IECs. For instance, $\alpha 5 \beta 1$ is found at the base of crypt and villus, $\alpha 2$ and $\alpha 3$ are expressed at the basolateral domains of enterocytes under distinctive crypt-villus, while $\alpha 5$ was detected along the crypt-villus axis showing a faint punctate/interrupted pattern [1].

A number of studies have focused on the importance of integrins in the regulation of programmed cell death in various contexts. Overexpression of the integrin $\alpha 5$ subunit in rat small intestinal epithelial cells conferred protection against several proapoptotic stimuli, while overexpression of the integrin $\alpha 2$ subunit had no effect on cell survival [21]. Downregulation of expression and functional activity of $\alpha 2 \beta 1$ integrin is associated with apoptosis induced by butyrate in colorectal cancer cells [22]. Death-associated protein kinase induces apoptosis by suppressing integrin functions and integrin-mediated survival signals in epithelial cells [23]. In tubular epithelial cells, enhanced expression of $\alpha 3, \alpha \mathrm{V}$, and $\beta 1$ subunits and redistribution of these subunits have defined roles in the development of the renal injury [24].

In our study, using laser confocal microscopy, we observed changes in polarity and distribution of integrins under ischemia/anoxia injury. In control groups, integrins 
$\alpha 3, \alpha 5, \beta 1$ and $\beta 5$ were mainly located at the basal surface of IECs, while after ischemia/anoxia, these subunits diffused to the apical surface of the cells and were accompanied by cell detachment and apoptosis. Integrin $\alpha 2$ was an exception, as no obvious redistribution was observed in our study suggesting that not all subunits of integrin take part in the IEC injury induced by ischemia/anoxia.

A number of studies have demonstrated relationships between calcium and integrin distribution. For example, calcium concentration appears related to the distribution of $\beta 4$ integrin epitopes in cultured keratinocytes [25]. Calcium channel blockers exert an effect on the cytoskeleton of tumor cells leading to inhibition of mobility and function of the alpha IIb beta 3 receptor [26]. Furthermore, the calciumchannel blocker, mibefradil, impairs integrin distribution and organization of the cytoskeleton in lens epithelial cell [27]. Our data also suggest that the changes in integrin distribution that occur following ischemia/anoxia are related to calcium overload. Specifically, verapamil treatment partially prevented the injury-induced redistribution leaving the integrin patterns more closely resembling those of the control group.

It is well established that integrins require a connection with the cytoskeleton to perform their roles. In most cases this connection is with the actin cytoskeleton. Activation and ligand binding of integrins lead to an extended extracellular conformation and separation of the cytoplasmic domains, exposing the $\beta$ subunit cytoplasmic domain and allowing it to initiate interactions with the actin cytoskeleton [28]. Cytoskeletal alterations have been reported to induce apoptosis in a variety of models, with special attention being focused on disassembly of the actin network. In addition, the change in actin cytoskeleton promotes apoptosis in human airway epithelial cells [29], rat and porcine proximal tubule epithelial cells [30], and also in other renal ischemiareperfusion (I/R) models [31]. Stabilizing F-actin may be responsible for the protection against hepatic ischemia in vivo by reducing apoptosis [32]. In the present study, actin depolymerization occurred under ischemia/anoxia in vitro which was together with the change of integrins and induced cell detachment and apoptosis. Verapamil may lead to aggregation of the actin cytoskeleton which exerts a protective effect on IECs limiting detachment and apoptosis.

A recently published study provided clear evidence for integrins in downregulating actin-based structures [33], while exactly how the actin cytoskeleton feeds back to the integrin-based adhesion remains less clear. In our study, we observed changes in integrin distribution and F-actin formation, but the temporal relationships between these factors are not clear. At this point, there is little evidence to suggest that calcium overload directly affects the integrins; however effect of intracellular calcium levels on the actin cytoskeleton has been accepted for many years. For instance, $\mathrm{Ca}^{2+}$ influx has the ability to interfere with the structure of the actin cytoskeleton in a variety of neuron cell types [34]. Further, $\mathrm{Ca}^{2+}$ levels are associated with the disassembly of F-actin in intestinal microvilli [35]. Thus we speculate that calcium overload, induced by ischemia/anoxia, may affect the distribution of integrins through the depolymerization of Factin. This hypothesis, however, requires further verification.

In conclusion, in the present study we found that ischemia/anoxia-induced injury in IECs leads to an altered integrin distribution and depolymerization of F-actin. Associated with these changes were increases in apoptosis and cell shedding. Evidence was provided that calcium overload following ischemia/anoxia may be an underlying mechanism in these responses. Thus, a calcium channel blocker both decreased the extent of exfoliation and apoptosis and reduced the alterations in integrin distribution and actin assembly. Further studies are required to determine the exact relationship between the integrin and actin cytoskeleton in the ischemia/anoxia-induced events and to verify that these mechanisms translate to the in vivo situation.

\section{Acknowledgments}

This work was financially supported by a Grant (30271286) from the National Natural Science Foundation Commission of China. The authors thank the Shanghai Institute of Biochemistry and Cell Biology for providing access to the confocal laser scanning microscope and their technical guidance to this paper.

\section{References}

[1] K. A. Powers, J. Zurawska, K. Szaszi, R. G. Khadaroo, A. Kapus, and O. D. Rotstein, "Hypertonic resuscitation of hemorrhagic shock prevents alveolar macrophage activation by preventing systemic oxidative stress due to gut ischemia/reperfusion," Surgery, vol. 137, no. 1, pp. 66-74, 2005.

[2] Y. Q. Lu, X. J. Cai, L. H. Gu, Q. Wang, W. D. Huang, and D. G. Bao, "Early difference in apoptosis of intestinal mucosa of rats with severe uncontrolled hemorrhagic shock after three fluid resuscitation methods," Chinese Medical Journal, vol. 119, no. 10, pp. 858-863, 2006.

[3] M. R. W. Grotz, E. A. Deitch, J. Ding, D. Xu, Q. Huang, and G. Regel, "Intestinal cytokine response after gut ischemia: role of gut barrier failure," Annals of Surgery, vol. 229, no. 4, pp. 478-486, 1999.

[4] J. C. Liang, H. R. Chen, C. C. Chiu, S. F. Liou, I. J. Chen, and J. L. Yeh, "Protective effect of labedipinedilol-A, a novel dihydropyridine-type calcium channel blocker, on myocardial apoptosis in ischemia-reperfusion injury," Life Sciences, vol. 79, no. 13, pp. 1248-1256, 2006.

[5] R. Bull, J. P. Finkelstein, J. Gálvez et al., "Ischemia enhances activation by $\mathrm{Ca}^{2+}$ and redox modification of ryanodine receptor channels from rat brain cortex," Journal of Neuroscience, vol. 28, no. 38, pp. 9463-9472, 2008.

[6] H. Wang, X. Yang, Z. Zhang, and H. Xu, "Both calcium and ROS as common signals mediate $\mathrm{Na}_{2} \mathrm{SeO}_{3}$-induced apoptosis in SW480 human colonic carcinoma cells," Journal of Inorganic Biochemistry, vol. 97, no. 2, pp. 221-230, 2003.

[7] W. T. Chiu, Y. H. Wang, M. J. Tang, and M. R. Shen, "Soft substrate induces apoptosis by the disturbance of $\mathrm{Ca}^{2+}$ homeostasis in renal epithelial LLC-PK1 cells," Journal of Cellular Physiology, vol. 212, no. 2, pp. 401-410, 2007.

[8] A. M. Raafat, M. T. Murray, T. McGuire et al., "Calcium blockade reduces renal apoptosis during ischemia reperfusion," Shock, vol. 8, no. 3, pp. 186-192, 1997. 
[9] F. Gao, B. Gong, T. A. Christopher, B. L. Lopez, A. Karasawa, and X. L. Ma, "Anti-apoptotic effect of benidipine, a long-lasting vasodilating calcium antagonist, in ischaemic/reperfused myocardial cells," British Journal of Pharmacology, vol. 132, no. 4, pp. 869-878, 2001.

[10] A. P. Gilmore, "Anoikis," Cell Death and Differentiation, vol. 12, no. 2, pp. 1473-1477, 2005.

[11] J. Grossmann, K. Walther, M. Artinger, S. Kiessling, and J. Schölmerich, "Apoptotic signaling during initiation of detachment-induced apoptosis ("anoikis") of primary human intestinal epithelial cells," Cell Growth and Differentiation, vol. 12, no. 3, pp. 147-155, 2001.

[12] D. Oguey, P. W. George, and C. Rüegg, "Disruption of integrin-dependent adhesion and survival of endothelial cells by recombinant adenovirus expressing isolated $\beta$ integrin cytoplasmic domains," Gene Therapy, vol. 7, no. 15, pp. 12921303, 2000.

[13] C. C. Park, H. Zhang, M. Pallavicini et al., " $\beta 1$ integrin inhibitory antibody induces apoptosis of breast cancer cells, inhibits growth, and distinguishes malignant from normal phenotype in three dimensional cultures and in vivo," Cancer Research, vol. 66, no. 3, pp. 1526-1535, 2006.

[14] N. E. Joo, T. Watanabe, C. Chen, M. Chekenya, W. B. Stallcup, and Y. L. Kapila, "NG2, a novel proapoptotic receptor, opposes integrin alpha4 to mediate anoikis through PKCalpha-dependent suppression of FAK phosphorylation," Cell Death \& Differentiation, vol. 15, no. 5, pp. 899-907, 2008.

[15] D. G. Stupack and D. A. Cheresh, "Get a ligand, get a life: integrins, signaling and cell survival," Journal of Cell Science, vol. 115, no. 19, pp. 3729-3738, 2002.

[16] R. Beck, B. Nebe, R. Guthoff, and J. Rychly, "Inhibition of lens epithelial cell adhesion by the calcium antagonist Mibefradil correlates with impaired integrin distribution and organization of the cytoskeleton," Graefe's Archive for Clinical and Experimental Ophthalmology, vol. 239, no. 6, pp. 452-458, 2001.

[17] G. S. Evans, N. Flint, A. S. Somers, B. Eyden, and C. S. Potten, "The development of a method for the preparation of rat intestinal epithelial cell primary cultures," Journal of Cell Science, vol. 101, no. 1, pp. 219-231, 1992.

[18] H. W. Chen, C. T. Chien, S. L. Yu, Y. T. Lee, and W. J. Chen, "Cyclosporine A regulate oxidative stress-induced apoptosis in cardiomyocytes: mechanisms via ROS generation, iNOS and Hsp70," British Journal of Pharmacology, vol. 137, no. 6, pp. 771-781, 2002.

[19] S. Y. Zheng, X. B. Fu, J. G. Xu, J. Y. Zhao, T. Z. Sun, and W. Chen, "Inhibition of p38 mitogen-activated protein kinase may decrease intestinal epithelial cell apoptosis and improve intestinal epithelial barrier function after ischemiareperfusion injury," World Journal of Gastroenterology, vol. 11, no. 5, pp. 656-660, 2005.

[20] R. W. Schrier, P. E. Arnold, V. J. Van Putten, and T. J. Burke, "Cellular calcium in ischemic acute renal failure: role of calcium entry blockers," Kidney International, vol. 32, no. 3, pp. 313-321, 1987.

[21] J. W. Lee and R. L. Juliano, “ $\alpha 5 \beta 1$ integrin protects intestinal epithelial cells from apoptosis through a phosphatidylinositol 3-kinase and protein kinase B-dependent pathway," Molecular Biology of the Cell, vol. 11, no. 6, pp. 1973-1987, 2000.

[22] A. Buda, D. Qualtrough, M. A. Jepson, D. Martines, C. Paraskeva, and M. Pignatelli, "Butyrate downregulates $\alpha 2 \beta 1$ integrin: a possible role in the induction of apoptosis in colorectal cancer cell lines," Gut, vol. 52, no. 5, pp. 729-734, 2003.
[23] W. J. Wang, J. C. Kuo, C. C. Yao, and R. H. Chen, "DAPkinase induces apoptosis by suppressing integrin activity and disrupting matrix survival signals," Journal of Cell Biology, vol. 159, no. 1, pp. 169-179, 2002.

[24] I. Londoño, S. Bamri-Ezzine, D. Gingras, and M. Bendayan, "Redistribution of integrins in tubular epithelial cells during diabetic glycogen nephrosis," Nephron, vol. 98, no. 1, pp. e22e30, 2004.

[25] J. Ryynanen, S. Jaakkola, E. Engvall, J. Peltonen, and J. Uitto, "Expression of $\beta 4$ integrins in human skin: comparison of epidermal distribution with $\beta 1$-integrin epitopes, and modulation by calcium and vitamin D3 in cultured keratinocytes," Journal of Investigative Dermatology, vol. 97, no. 3, pp. 562$567,1991$.

[26] J. Timar, H. Chopra, X. Rong et al., "Calcium channel blocker treatment of tumor cells induces alterations in the cytoskeleton, mobility of the integrin $\alpha$ (IIb) $\beta 3$ and tumorcell-induced platelet aggregation," Journal of Cancer Research and Clinical Oncology, vol. 118, no. 6, pp. 425-434, 1992.

[27] R. Beck, B. Nebe, R. Guthoff, and J. Rychly, "Inhibition of lens epithelial cell adhesion by the calcium antagonist Mibefradil correlates with impaired integrin distribution and organization of the cytoskeleton," Graefe's Archive for Clinical and Experimental Ophthalmology, vol. 239, no. 6, pp. 452-458, 2001.

[28] I. Delon and N. H. Brown, "Integrins and the actin cytoskeleton," Current Opinion in Cell Biology, vol. 19, no. 1, pp. 43-50, 2007.

[29] S. R. White, P. Williams, K. R. Wojcik et al., "Initiation of apoptosis by actin cytoskeletal derangement in human airway epithelial cells," American Journal of Respiratory Cell and Molecular Biology, vol. 24, no. 3, pp. 282-294, 2001.

[30] B. van de Water, J. F. Nagelkerke, and J. L. Stevens, "Dephosphorylation of focal adhesion kinase (FAK) and loss of focal contacts precede caspase-mediated cleavage of FAK during apoptosis in renal epithelial cells," Journal of Biological Chemistry, vol. 274, no. 19, pp. 13328-13337, 1999.

[31] M. Genescà, A. Sola, and G. Hotter, "Actin cytoskeleton derangement induces apoptosis in renal ischemia/reperfusion," Apoptosis, vol. 11, no. 4, pp. 563-571, 2006.

[32] S. W. C. Chen, S. W. Park, M. Kim, K. M. Brown, V. D. D’Agati, and H. T. Lee, "Human heat shock protein 27 overexpressing mice are protected against hepatic ischemia and reperfusion injury," Transplantation, vol. 87, no. 10, pp. 1478-1487, 2009.

[33] L. A. Davidson, M. Marsden, R. Keller, and D. W. DeSimone, "Integrin $\alpha 5 \beta 1$ and fibronectin regulate polarized cell protrusions required for Xenopus convergence and extension," Current Biology, vol. 16, no. 9, pp. 833-844, 2006.

[34] M. Cristofanilli and A. Akopian, "Calcium channel and glutamate receptor activities regulate actin organization in salamander retinal neurons," Journal of Physiology, vol. 575, no. 2, pp. 543-554, 2006.

[35] J. R. Glenney, A. Bretscher, and K. Weber, "Calcium control of the intestinal microvillus cytoskeleton: its implications for the regulation of microfilament organizations," Proceedings of the National Academy of Sciences of the United States of America, vol. 77, no. 11, pp. 6458-6462, 1980. 

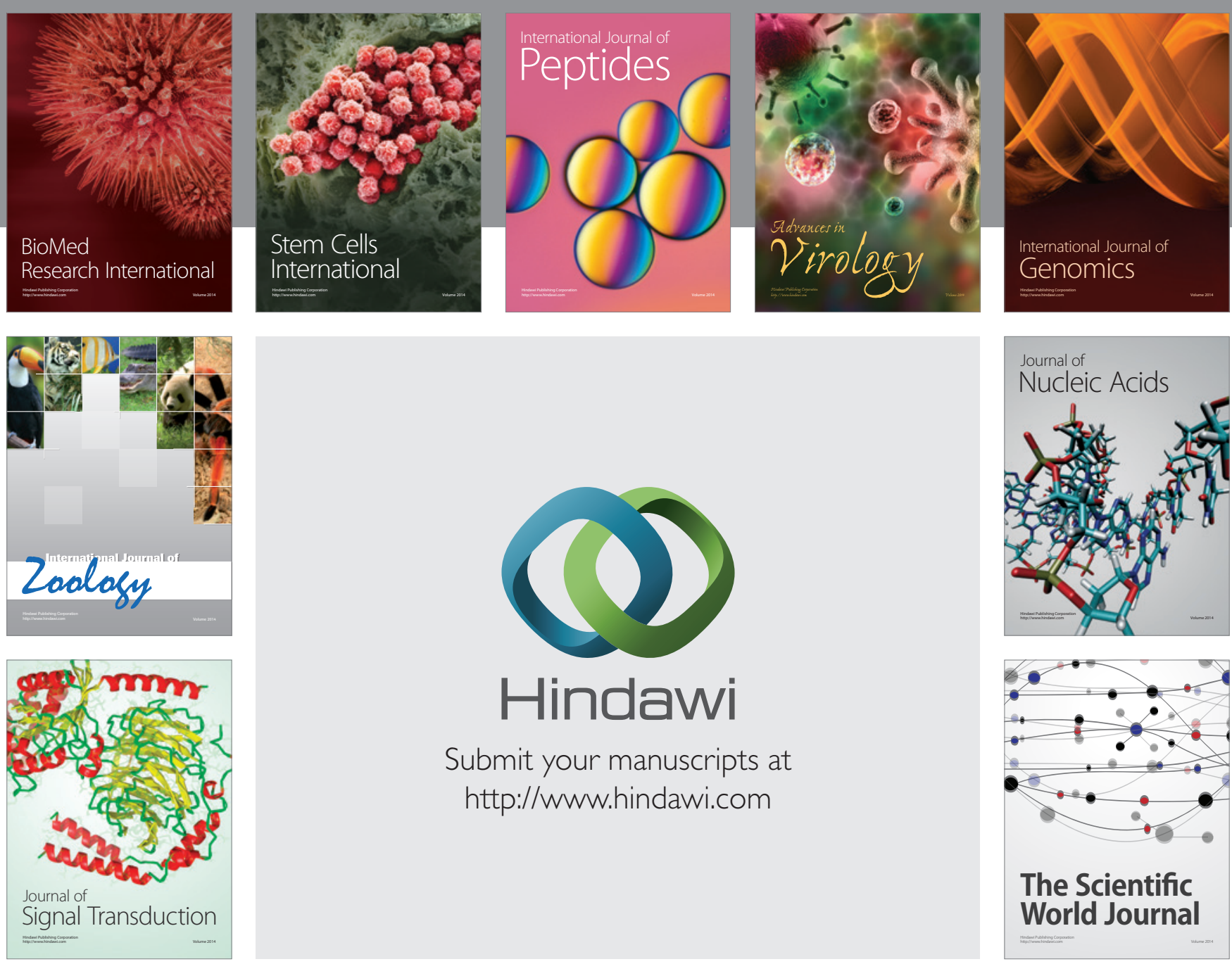

Submit your manuscripts at

http://www.hindawi.com
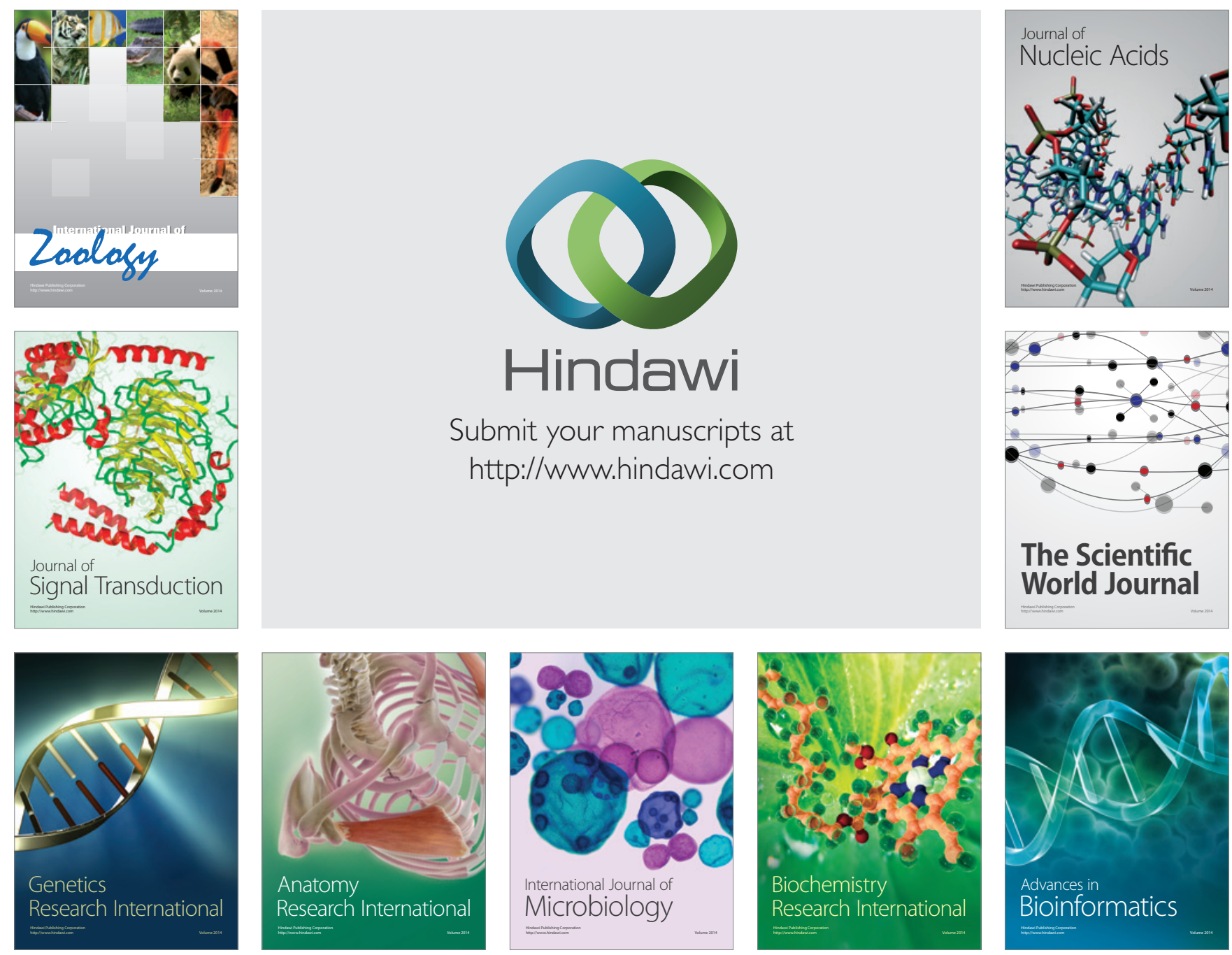

The Scientific World Journal
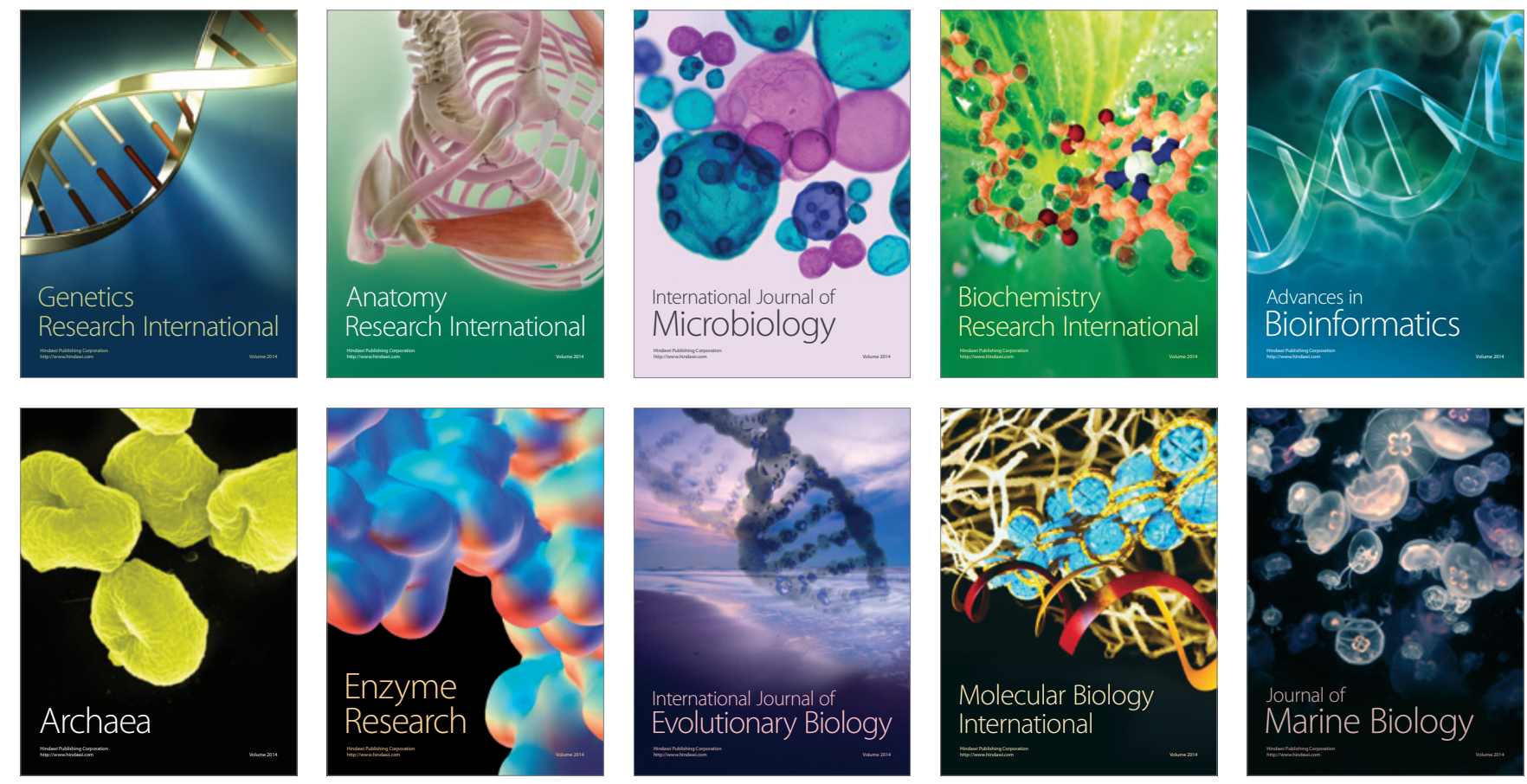